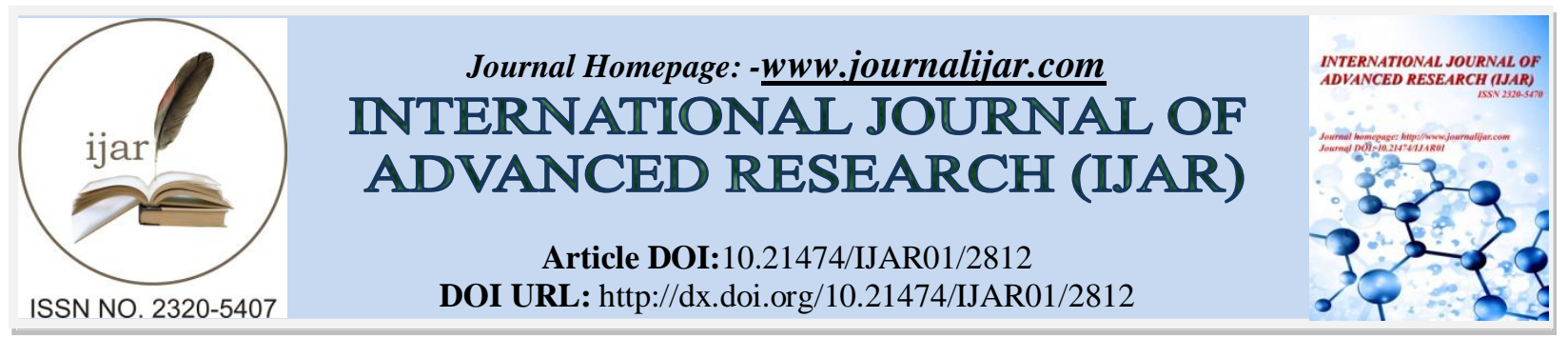

RESEARCH ARTICLE

\title{
COMPARITIVE EVALUATION OF SALIVARY Ig A LEVELS AND DENTAL CARIES IN OBESE AND NON OBESE CHILDREN.
}

\section{"Dr. B. Jagadesh Babu M.D.S ${ }^{1}$, Dr. N. Venugopal Reddy M.D.S ${ }^{2}$, Dr. B. V. Thimma Reddy M.D.S ${ }^{3}$, Dr. V. Daneswari M.D.S ${ }^{4}$ and Dr. Niharika Puppala M.D.S ${ }^{5}$.}

1. Senior lecturer, Dept of Pediatric Dentistry, Sree Sai Dental College \& Research Institute, Srikakulam; A.P.

2. Professor \& HOD, Dept of Pediatric Dentistry, Mamata Dental College, Khammam; Telangana State.

3. Professor, Dept of Pediatric Dentistry, Panineeya Institute Of Dental Sciences, Hyderabad; Telangana State.

4. Professor, Dept of Pediatric Dentistry, Mamata Dental College, Khammam; Telangana State.

5. Reader, Dept of Pediatric Dentistry, Mamata Dental College, Khammam; Telangana State.

\section{Manuscript Info}

Manuscript History

Received: 15 November 2016

Final Accepted: 17 December 2016

Published: January 2017

Key words:-

Salivary Ig A, Obese, Non obese, deft, DMFT

\section{Abstract}

Aim: The aim of the present study was to compare the S ig A levels and dental caries in obese and non obese children.

Materials and Methods: Eighty normal healthy children in the age group of eight to twelve were selected and divided into two groups, Obese(Group I, $n=40$ ) and Nonobese(Group II, $n=40$ ). Each group was further divided into two sub groups as carious $(n=20)$, and non carious $(n=20)$ based on deft/DMFT score. From all the children $2 \mathrm{ml}$ of unstimulated saliva collected and S IgA levels were estimated by using ELISA method.

Results: The difference between S Ig A levels and dental caries in obese and non obese was not statistically significant where as intragroup(carious and non carious) S IgA levels were significantly higher in carious free sub group than carious sub group in both groups.

Conclusion: Higher levels of S ig A in caries-free mouth can be attributed for protection against dental caries. From the present study, it was concluded that obesity has no effect on $\mathrm{S}$ ig A levels.

Copy Right, IJAR, 2016,. All rights reserved.

\section{Introduction:-}

Dental caries is an infectious microbial disease with a multifactorial origin that continues to be the most common chronic disease in humans affecting nearly the entire population. ${ }^{1}$ Human saliva not only lubricates the oral tissues, making oral functions such as speaking, eating, and swallowing possible, but also protects teeth and oral mucosal surfaces in different ways. Recent studies have revealed a large number of functions, mediated by both the inorganic and organic components of saliva, that should be considered in assessments of the effects of human saliva on dental caries. Some genetically regulated salivary components like immunoglobulins may influence both the colonization and the clearance of microorganisms from the oral cavity. ${ }^{2}$ Out of all five classes (IgA, $\left.\operatorname{IgD}, \operatorname{IgE}, \operatorname{IgG}, \operatorname{IgM}\right)$ of immunoglobulins secretory IgA is the main immunoglobulin in salivary secretions. Salivary secretory immunoglobulin A (S IgA) has an immunological control over dental caries and presumably prevents the adherence of cariogenic microorganisms to hard surfaces and may also inhibit the activity of glucosyltransferases. 
Childhood obesity is also one of the most serious public health challenges of the $21^{\text {st }}$ century. The problem is global and is steadily affecting many low and middle income countries, particularly in urban settings, and prevalence has increased at an alarming rate. Worldwide, the numbers of over weight children under the age of five is estimated to be over 42 million, and close to 35 million of these are living in developing countries. ${ }^{4}$ Diet plays an important role in the increased prevalence of obesity due to the higher consumption of foods rich in fat and carbohydrates. Overweight or obese children and adolescents reported higher consumption of sugary drinks and foods such as "fast food" compared with those who reported normal weight. Besides been directly associated with obesity, eating habits, especially regarding the intake of sucrose, have a well established causal relationship with tooth decay. ${ }^{5}$ Recent studies have revealed that there are significant relations which occur between salivary immunoglobulin $\mathrm{A}(\mathrm{SIgA})$ levels and dental caries ${ }^{6,7,8}$ body mass index(B.M.I) and dental caries in children. ${ }^{9,10,11}$ The purpose of the present study is to compare the salivary IgA levels and dental caries in obese and non obese children.

\section{Methodology:-}

Sample selection:

The present study was conducted in the Department of Pedodontics and Preventive Dentistry, Mamata Dental College and Hospital, Khammam in association with Department of Microbiology and Immunology, Mamata General Hospital, Khammam. The study was approved by Ethical Review Board.

A total of 80 school going children aged between 8-12 years were selected randomly for the present study based on the following inclusion and exclusion criteria after obtaining informed consent from the parents.

Inclusion criteria:

Children with normal growth and development

Children with good oral hygiene.

Children without any systemic disorders.

Exclusion criteria:

Children with upper respiratory tract infection

Medically compromised children and children with systemic disorders.

Children having history of antibiotics intake in past 7 days.

Children have oral exposure to food before two hours of sample collection.

Anthropometric measurements:

Anthropometric measurements were taken prior to the dental examination.The height without shoes was measured with a height measuring charts. The weight was assessed using a digital weighing machine. The BMI was calculated as the weight divided by the square of the height $(\mathrm{kg} / \mathrm{m} 2)$. The caliculated BMI was considered as obese according to the Centers for Disease Control and Prevention's (CDC) BMI-for-age growth charts.

\section{Dental examination:}

A caries assessment was performed with a mouth mirror and a probe under clinical conditions by single examiner. All the children were selected during routine dental camps conducted by the department of pediatric and preventive dentistry, Mamata Dental College \& Hospital,Khammam.

Each group was again divided into two sub groups of each 20 as Carious and Non carious groups based on the WHO criteria 1997.

\section{Saliva Collection ${ }^{12}$ :}

Salivary samples were collected between $10 \mathrm{AM}$ to $12 \mathrm{PM}$ in order to prevent any differences in the concentration of saliva due to circadian rhythm. Patients were informed not to eat or drink one hour before saliva collection to minimize possible food debris and stimulation of saliva. The child was seated in a well-ventilated and well-lit room. The head was kept at 45 degrees flexion with one hand holding a disposable vial for 2 minutes in a calm atmosphere to simulate unstimulated conditions. The saliva was allowed to drip into the sterile vial held to the lower lip for collection of $2 \mathrm{ml}$ of unstimulated saliva. If the saliva sample was insufficient within 2 minutes, the collection was continued until $3 \mathrm{ml}$ of saliva per subject was obtained.

\section{Determination of S Ig A level:}

Saliva collected from children were centrifuged and supernatant was added to prepared salivary diluents. Diluted antibody enzyme conjugate was added to standard, control, unknown samples and incubated for 90 minutes at room temperature.50 $\mu 1$ of sample from each tube was added to appropriate wells and covered plate with adhesive plate sealer. Washed wells 6 times with wash buffer and added TMB solution. $50 \mu$ l of stop solution was added to all wells 
and waited until all wells turned from blue(fig 3) to yellow (fig 4). Then read in a plate reader at $450 \mathrm{~nm}$ for S IgA levels.

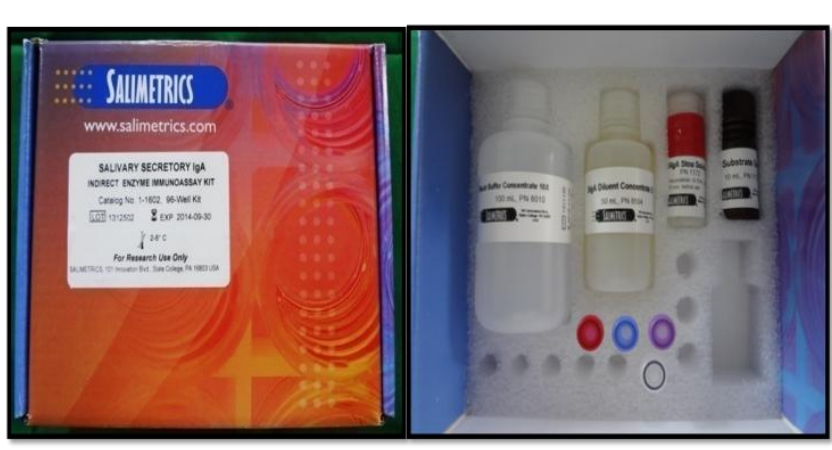

Fig 1. S Ig A Elisa kit

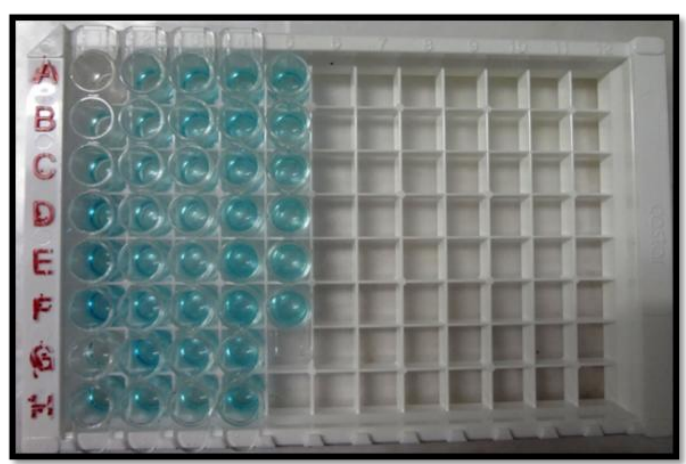

Fig 3 Before adding stop solution

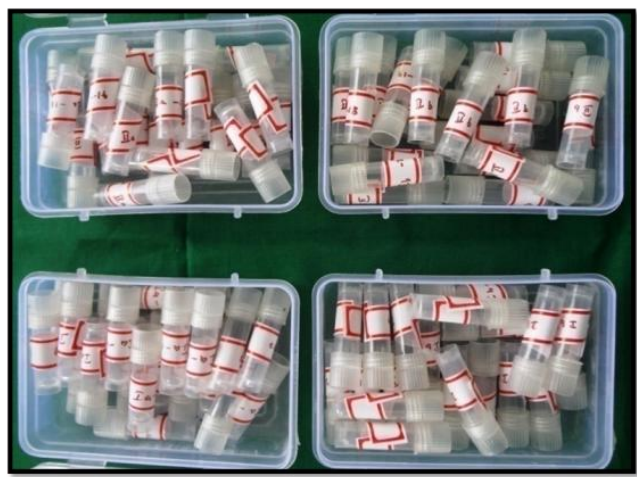

Fig 2 - Collected saliva samples

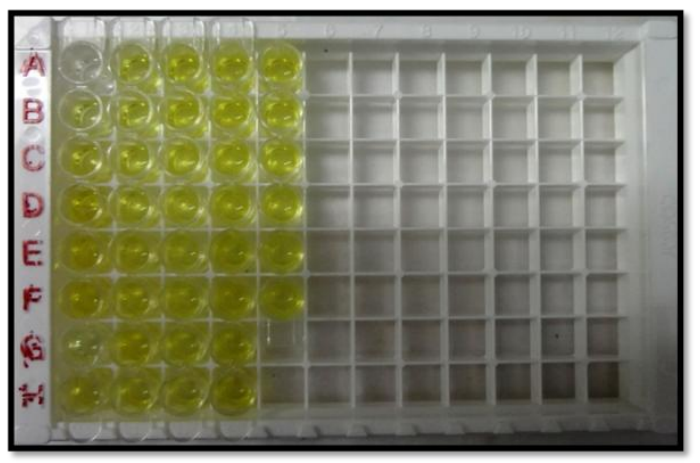

Fig 4 After adding stop solution

\section{Results:-}

The results obtained were subjected to statistical analysis. The mean values, standard deviation (SD) for both the groups were analyzed using the "Statistical Package for the Social Sciences" (SPSS) software, version 16.0.A $p$ value of $<0.05$ was considered as statistically "significant" and a $p$ value $<0.001$ was considered as statistically "highly significant".

Intra group comparison shows mean S Ig A levels for obese carious children is $157.05 \mu \mathrm{g} / \mathrm{ml}$ and $182.8 \mu \mathrm{g} / \mathrm{ml}$ for non carious children (Graph 1\& Table 1).Intra group comparison of mean S Ig A levels for Non obese group is $158.55 \mu \mathrm{g} / \mathrm{ml}$ in carious and $183.8 \mu \mathrm{g} / \mathrm{ml}$ for non carious children (Graph 2\& Table 2).S IgA levels were significantly higher in carious free sub group than carious sub group in both obese and non obese groups (Graph 3 \& Table 3). Inter group comparison of mean S IgA levels for Obese children is $169.92 \mu \mathrm{g} / \mathrm{ml}$ and $171.17 \mu \mathrm{g} / \mathrm{ml}$ in Non obese children (Graph 4\&Table 4). There is difference between S Ig A levels and dental caries in Obese and Non obese group but the difference is not statistically significant (p:0.9963)

\begin{tabular}{|l|l|l|l|l|l|}
\hline & & Age & BMI & DMFT/deft & S Ig A $(\mu \mathrm{g} / \mathrm{ml})$ \\
\hline \multirow{3}{*}{ Carious } & Mean & 10.7 & 34.33 & 3.85 & 157.05 \\
\cline { 2 - 6 } & SD & 1.38 & 6.81 & 0.93 & 42.14 \\
\hline \multirow{2}{*}{ Non carious } & Mean & 10.7 & 30.3 & 0.00 & 182.80 \\
\cline { 2 - 6 } & SD & 1.45 & 0.97 & 0.00 & 33.95 \\
\hline
\end{tabular}

Table 1:- Mean \& SD for age, BMI, DMFT/deft \& S-Ig A values for Obese group

\begin{tabular}{|l|l|l|l|l|l|}
\hline & & Age & BMI & DMFT/deft & S Ig A $(\mu \mathrm{g} / \mathrm{ml})$ \\
\hline \multirow{2}{*}{ Carious } & Mean & 10.00 & 21.02 & 3.8 & 158.55 \\
\cline { 2 - 6 } & SD & 1.33 & 1.93 & 1.00 & 30.24 \\
\hline Non carious & Mean & 8.9 & 20.12 & 0.00 & 183.80 \\
\hline
\end{tabular}




\begin{tabular}{|l|l|l|l|l}
\hline SD & 0.71 & 1.97 & 0.00 & 19.37
\end{tabular}

Table 2:- Mean \& SD for age, BMI, DMFT/deft \& S-Ig A values for Non obese group

\begin{tabular}{|c|c|c|c|c|c|}
\hline Group & Sub group & & DMFT/deft & $\mathrm{S} \operatorname{Ig} \mathrm{A}((\mu \mathrm{g} / \mathrm{ml})$ & $\mathrm{p}$-value \\
\hline \multirow[t]{4}{*}{ Obese } & \multirow[t]{2}{*}{ Carious } & Mean & 3.85 & 157.05 & \multirow[b]{4}{*}{$0.0032^{*}$} \\
\hline & & SD & 0.93 & 42.14 & \\
\hline & \multirow[t]{2}{*}{ Non carious } & Mean & 0.00 & 182.80 & \\
\hline & & SD & 0.00 & 33.95 & \\
\hline \multirow[t]{4}{*}{ Non obese } & \multirow[t]{2}{*}{ Carious } & Mean & 3.8 & 158.55 & \multirow{4}{*}{0.0399} \\
\hline & & SD & 1.00 & 30.24 & \\
\hline & \multirow[t]{2}{*}{ Non carious } & Mean & 0.00 & 183.80 & \\
\hline & & SD & 0.00 & 19.37 & \\
\hline
\end{tabular}

$* \mathrm{p}<0.05$

Table No 3:- Intra group comparison of dental caries status and salivary IgA levels by Unpaired t- test

\begin{tabular}{|l|l|l|l|l|}
\hline Group & & DMFT/deft & S Ig A $(\mu \mathrm{g} / \mathrm{ml})$ & p-value \\
\hline Obese & Mean & 1.925 & 169.92 & \\
\hline Non obese & Mean & 1.9 & 171.17 & 0.9963 \\
\hline
\end{tabular}

Table No 4:- Inter group comparison of dental caries status and salivary IgA levels by ANOVA test

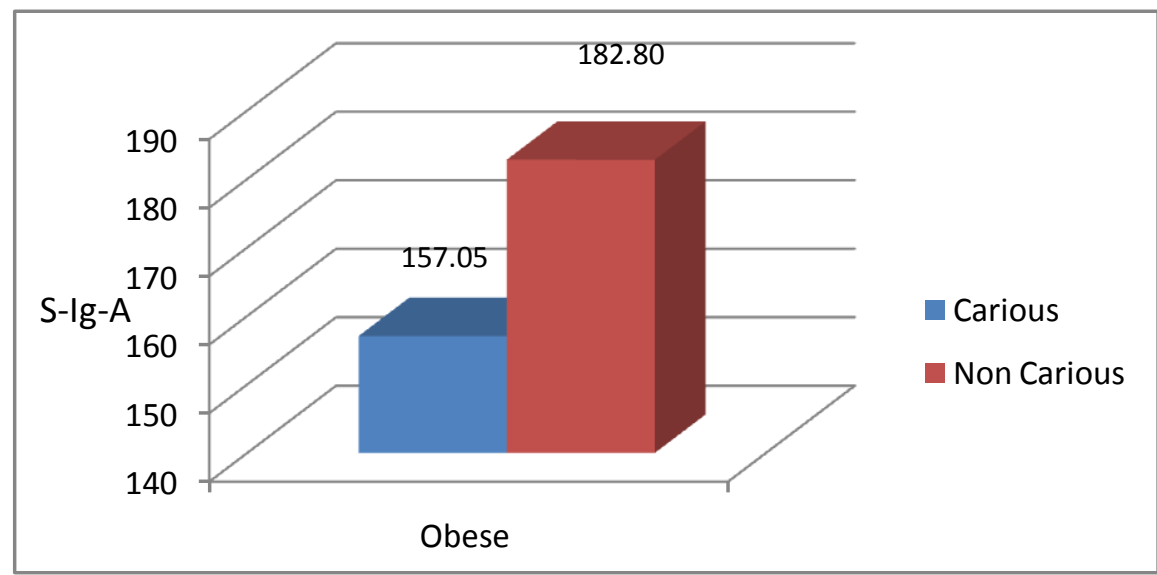

Graph 1:- Intra group comparison of S IgA levels in Obese children

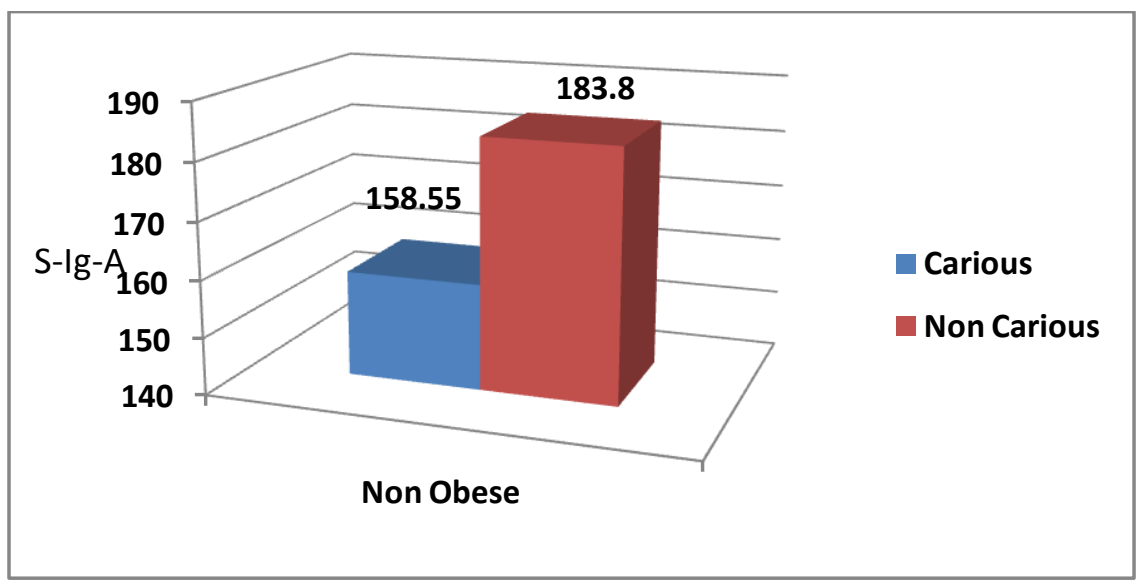

Graph 2:- Intra group comparison of salivary IgA levels in Non obese children 


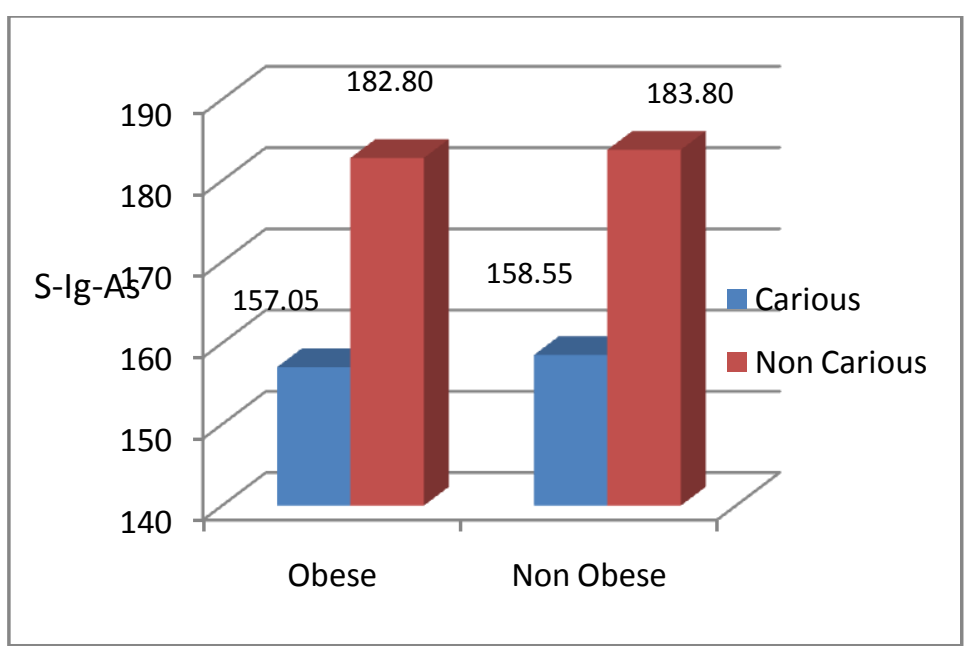

Graph 3:- Inter group comparison of salivary'-IgA levels

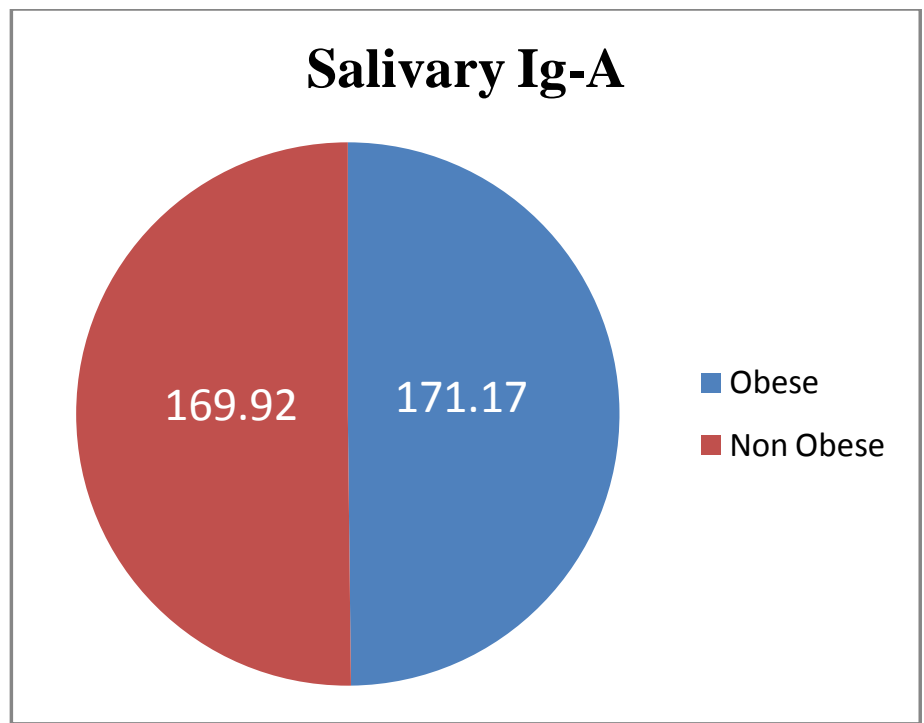

Graph 4:-Inter group comparison of mean salivary Ig A levels

\section{Discussion:-}

Dental caries is a multifactorial disease and one of the major contributing factors is saliva. Secretory immunoglobulin A (S IgA) is the prominent immunoglobulin in whole saliva and is considered to be the main specific defence mechanism in the oral cavity. S IgA helps in prevention of dental caries by inhibition of bacterial adherence, reduction of hydrophobicity, agglutination of bacteria and inactivation of bacterial enzymes and toxins. Several studies on the role of S IgA in prevention of dental caries showed contradictory results. ${ }^{13}$

Overweight and obesity among children are a major public health concern, especially in developing countries. There are many reasons for the obesity like fast food contributes to a high-energy consumption, and a sedentary life style reduces energy expenditure. Indeed, many of the foods, including soft drinks and refined-wheat breads, are low in micronutrients. ${ }^{14}$

Increased SIgA levels are seen in Wiskott-Aldrich syndrome, Cirrhosis of the liver, IgA myeloma, Autoimmune disorders, Rheumatoid arthritis, Lupuserythromatosis etc. Where as decreased SIgA levels seen in Hereditary ataxia, Telangiectasia, Malabsorption syndromes, Lymphoid aplasia, Chronic lymphoblastic leukemia etc. Because of changes in salivary IgA levels in different diseases, present study excluded the children having health problems. ${ }^{15}$ 
Saliva was collected by the method suggested by Colin Dawes ${ }^{16}$ as it was easy to obtain the child's cooperation. All the samples were collected between10-11am. This time was two hours after any oral or visual exposure to food stuffs. This was done to prevent the effect of circadian rhythms on salivary concentrations. Edgar $\mathrm{M}^{17}$ found that the IgA \& protein concentration decreased with increased salivary flow from the parotid and submandibular salivary glands. Stimulated saliva could have decreased the concentration of the IgA, hence unstimulated whole saliva was collected for the study.

After collection of saliva, it is important to keep samples at or below $-20^{\circ} \mathrm{Cwithin} 4$ hours of collection from children to avoid bacterial growth in the specimen. In the present study salivary samples were stored at $-70^{\circ} \mathrm{C}$ to in cryo refrigerator prevent bacterial growth in collected salivary samples.

According to Fontana et $\mathrm{al}^{18}$ establishment of disease depends on the relative incapacity of the host to provide effective specific and nonspecific protective barriers and on the ability of the microorganism to adhere and to overcome these barriers. Pathogenic microorganisms must overcome the host nonspecific defence barriers (e.g., cleansing mechanisms such as coughing, swallowing, and fluid flow) and must also escape recognition by soluble immune or non immune host molecules in host secretions. Secretory IgA antibodies may bind to surface antigens of microorganisms in saliva, causing them to agglutinate, thereby facilitating their rapid elimination and prevent from dental caries. Salivary IgA antibodies can mediate $S$. mutans colonization. If glycosyltransferase (GTF) enzyme is bound to $S$. mutans fimbriae, enzyme neutralization by $\operatorname{IgA}$ antibody may inhibit $S$. mutans enzyme activities and, therefore, cariogenicity by reducing both the colonization by $S$. mutans and the virulence of the organism.

Fontana et $\mathrm{al}^{18}$ suggests that caries free subjects may be protected immunologically from dental caries by salivary IgA antibody against $S$. mutans antigens. In the present study also salivary IgA levels were more children with less dental caries to give protection against dental caries. The results of present study were not in agreement with Thaweboon ${ }^{6}$, Chawda $\mathrm{GJ}^{7}$, Ranadheer $\mathrm{E}^{8}$ found higher salivary IgA levels in children with more dental caries which are contradictory to the present study.

The contradictory results seen in the literature may be due to difference in sampling methods, different criteria for patient selection, and different laboratory tests used between the studies. Moreover, the concentration of salivary immunoglobulin may change depending upon the salivary flow rate, hormonal factors, emotional states, and physical activity. ${ }^{6}$

A few studies conducted to find out the relation between body mass index(B.M.I) and dental caries in children and concluded that there was no relation between BMI and dental cariesTripathi ${ }^{11}$, Toumi et $\mathrm{al}^{19}$, Pinto ${ }^{20}$.On contradictory to these studies Larsson $\mathrm{B}^{9}$, Nava $\mathrm{FV}^{10}$, investigated the association between dental caries and $\mathrm{BMI}$ and sconcluded as there was an association between BMI and dental caries

\section{Conclusion:-}

Dental caries is a complex and dynamic process where a multitude off actors influence and initiate the progression of disease. Till to date studies on comparative evaluation of salivary Ig-A levels and dental caries in Obese and Non obese children are very less. The present study shows that there is a significant difference in IgA levels among carious and non carious children in both obese and non-obese conditions, but there is no significant difference between obese and non-obese conditions. From this present study it can be concluded that obesity does not make any difference in production of salivary immunoglobulins especially S IgA. Further studies are needed to confirm the role of S IgA on caries activity.

\section{References:-}

1. Omar OM, Khattab NMA, Rashed LA. Glucosyltransferase B, Immunoglobulin A, and cariesexperience among a group of Egyptian preschool children. J Dent Child 2012;79(2):63-8.

2. Lumikari ML, LoimarantaV.Saliva and dental caries. J Dent Res2000;14:40-7.

3. Pal S, Mitra M, Mishra J, Saha S, Bhattacharya B.Correlation of total salivary secretory immunoglobulin A (S$\operatorname{IgA}$ ) and mutans specific SIgA in children having different caries status. J Indian SocPedod Prevent Dent 2013;31( 4 ):270-4.

4. Guare RO, Ciamponi AL, Santos MTBR, Gorjao R, DinizMB.Caries experience and salivary parameters among overweight children and adolescents. J Dent 2013;1:31-40. 
5. Silva AMR, Menezes AMB, Demarco FF, Ferreira FV, Peres MA.Obesity and dental caries:systematicreview.RevSaudePublica 2013;47(4):799-812.

6. Thaweboon S, Thaweboon B, Nakornchai S, JitmaitreeS.Salivary secretory IgA, pH, flow rates, mutansstreptococci and candida in children with rampant caries. Southeast Asian J Trop Med Public Health 2008;38(5):893-9.

7. Chawada JG, Chaduvula N, Patel HR, Jain SS , LalaAK.SalivarySIgA and dental caries activity.Ind Pediatrics 2011;48:719-22.

8. Ranadheer E, Nayak UA, Reddy NV, RaoVAP.The relationship between salivary IgA levels and dental caries in children.J Indian SocPedod Prevent Dent 2011;29(2):106-12.

9. Larsson B, Johansson I, Hallmans G, Ericson T.Relationship between dental caries and risk factors for atherosclerosis in Swedish adolescents.Community Dent Oral Epidemiol 1995;23:205-10.

10. Francisco VN, Rodriguez EMV, Gonzalez AHS, Ochoa DL, Perales GMM, Velzquez VMJ. Association between obesity and dental caries in a group of preschool children in mexico. J Public Health Dent 2010;70:124-30.

11. Swati T, Kiran K, Kamala B. Relationship between obesity and dental caries in children - A preliminary study. J Int Oral Health 2010; 2 (4):65-72.

12. Katie P. Relationship between unstimulated salivary flow rate and saliva composition of healthy children in Taiwan. Chang Gung Med J 2008; 31:281-6.

13. Harry W,Schroeder, CavaciniL.Structure and function of immunoglobulins. J Allergy ClinImmunol 2010;125(2):S41-54.

14. Willershausen B, Moschos D, Azrak B, Blettner M. Correlation between oral health and body mass index (BMI) in 2071 primary school pupils. Eur J Med Res 2007;12:295 -9.

15. PanikerCKJ.Text book of microbiology. 7th Ed,OrientBlackswan publisher 2005,Pg no 37-39.

16. Dawes C.Circadian rhythms in the flow rate and composition of unstimulated and stimulated human submandibular saliva. J Physiol 1975:535-48.

17. Edgar M, Dawes C, MullaneDO.Saliva and oral health. 4th Ed,StephenHancocks Limited, 2012,Pg no 8-12.

18. Fontana M, Fell LEG, Gregory RL. Characterization of preparations enriched for streptococcus mutans fimbriae: Salivary immunoglobulin A antibodies in caries-free and caries-active subjects. ClinDiagn Lab Immunol 1995;2(6):719-25.

19. Tuomi T. Pilot study on obesity in caries prediction. Community Dent Oral Epidemiol 1989;17:289-91.

20. Pinto A, Kim S, Wadenya R, Rosenberg H. Is there an association between weight and dental caries among pediatric patients in an urban dental school? A correlation study. J Dent Edu 2007;71(11):1435-40. 